\title{
Factors of Success in Formation of Entrepreneurship Training Programs
}

\section{Panikarova Svetlana}

\author{
Doctor of Economics, Ural Federal University, Ekaterinburg, Russia, Senior Fellow at the Centre of Economic Theory \\ Institute of Economics, Ural Branch of the Russian Academy of Sciences; Ekaterinburg
}

\section{Doi:10.5901/mjss.2015.v6n5s1p446}

\begin{abstract}
In article the author presented results of the analysis of factors of efficiency of educational programs for business at universities of the different countries. As a result of the conducted researches, it is proved that a success major factor in formation of enterprise competences is existence of the full closed cycle of training and support of business from transfer of basic knowledge before real support of the beginning businessman and often subsequently consulting maintenance of the operating business.
\end{abstract}

Keywords: entrepreneurship; entrepreneurship training; educational program; teaching infrastructure; entrepreneurial competencies

\section{Introduction}

Entrepreneurship is an integral part of modern market economy without which economics of the country cannot properly function and develop. In the countries with developed economy from the point of view of economic position and level of life entrepreneurs form the basis of middle class which serves as the foundation of social and political stability of society. That is why development of small enterprises is the top priority of modern policy for a long - term perspective in many countries of post - soviet space. Strategic documents of many countries - former members of USSR necessarily formulate the task on developing smaller enterprises and stimulus for its activation. Professional associations uniting representatives of all enterprises have been created. Academic forums create special panels devoted to peculiar features of small entrepreneurship. A lot of research was conducted on the topic results of which were published in the form of articles and monographs and candidate and doctoral theses were defended. However despite the state interest, public attention and overall support development of smaller enterprises in the majority of post - Soviet countries lags behind the levels demonstrated by countries with developed market economy and official prognostication figures. This situation calls for research on instruments, methods and approaches to stimulating smaller enterprises. One aspect of this research is an attempt to answer the following question: what should entrepreneurship education in post - soviet countries look like?

Works of the following authors present examples of innovative approach to entrepreneurship training: E.A. Scherbakova (2012), S.V. Khachin (2012), L. Pittaway, C.Missing (2009), J. Zang, E. Hamilton (2010). Experience of training in innovative entrepreneurship in the context of a construction educational cluster in the system of technical and technological education is given in the work by R.S. Safin (2012). Certain problems faced by entrepreneurship education in Russia are highlighted in publications by N.S. Zaripova (2014), G.N. Franovskaya (2013) et al. Research on student entrepreneurship is made by G.V. Shirokova, A.V. Kulikova (2011). Works by J. Copp, G. Watts (2000), L. Bisk (2002) reveal the role of mentoring in entrepreneurship training. Development of pedagogical practices of entrepreneurship training is described by D.Kirby (2009). Peculiar features of entrepreneurship education in the online format are given in the research by B. Mashaw (2012), J. Mills and S. Barakat (2010).

At the same time analysis of main trends in academic research devoted to entrepreneurship training demonstrates insufficient amount of complex comparative research concentrating on efficacy factors in entrepreneurship training based on best practices of universities from different countries.

The aim of the research is to identify efficacy factors for entrepreneurship training programs on the basis of analysis of existing approaches to forming entrepreneurial competencies at the leading universities.

Two main research questions were placed:

1. What features of key competencies of entrepreneurship education are usual for leading universities?

2. What elements of system entrepreneurial competencies can be useful for typical university practice?

The structure of the paper is as follows: The first section presents the methods of research. The second section characterizes the entrepreneurial knowledge and skills during the process of teaching. The third section presents the 
special infrastructure elements for entrepreneurship education. The forth section presents the role of academic research and networking in the entrepreneurship education and the last section is the conclusion.

\section{Methods}

The article takes an eclectic methodological approach to piece together extant literature and to discover new empirical knowledge about the factors of efficiency of educational programs for business. Peculiar feature of author's approach is in attempt at complex comparative analysis of entrepreneurship educational programs offered by the leaders in the field in different aspects: starting from educational program content to peculiar features of training infrastructure.

The research uses economic, statistic and sociological methods of data collection, processing and analysis including expert questionnaires and interviews.

Research project consisted of three stages.

At the first stage with the help of experts author formed the list of educational organizations with best practices and approaches to entrepreneurship. Selection criteria included top rankings in national and international ratings; positive academic reputation; membership in regional and international associations of educational organizations; long successful experience of training entrepreneurs; successful research activities; possibility to disseminate successful experience of forming entrepreneurial competencies among educational institutions with developing educational environment. The list of universities whose programs were chosen for further analysis consisted of 24 higher educational institutions from 9 countries (including the USA, Great Britain, the Netherlands, Singapore, France, Canada, etc.).

The second stage included distant analysis of chosen educational programs according to the following parameters: educational program structure; teaching infrastructure; teaching personnel characteristics; academic and practical teaching environment characteristics. Informational sources for the second stage included web-sites of analyzed educational institutions; marketing materials received at Russian and international conferences; information from closed databases (ICSB и USASBE); materials provided for open access by regional and international unions and networks engaged in entrepreneurship training; printed and electronic Mass Media; portals in the relevant field.

The third stage included a series of structured interviews with representatives of leading organizations in the field of entrepreneurship education. This work was aimed at obtaining more detailed information on peculiar features of entrepreneurship education and clarification of certain results of previous analysis.

\section{Results}

Entrepreneurship training at leading universities usually has a complex character. The system of forming entrepreneurial competencies consists of several elements:

1) forming entrepreneurial knowledge and skills during the process of teaching;

2) supporting entrepreneurial activities with the help of developed infrastructure;

3) developing communicational space for entrepreneurial networking;

4) conducting academic research in the field of entrepreneurship.

Let's look at each of these elements in more detail.

\subsection{Forming entrepreneurial knowledge and skills during the process of teaching}

One of the main tasks of the research was to find out which competencies play the most important role in the training of future entrepreneurs from the point of view of heads of teaching programs under analysis. Interviews provided a relatively long list of different competencies which are considered as important by universities. In general these key competencies can be subdivided into three groups: competencies forming entrepreneurial thinking; entrepreneurial communication and entrepreneurial skills (Figure 1.). 


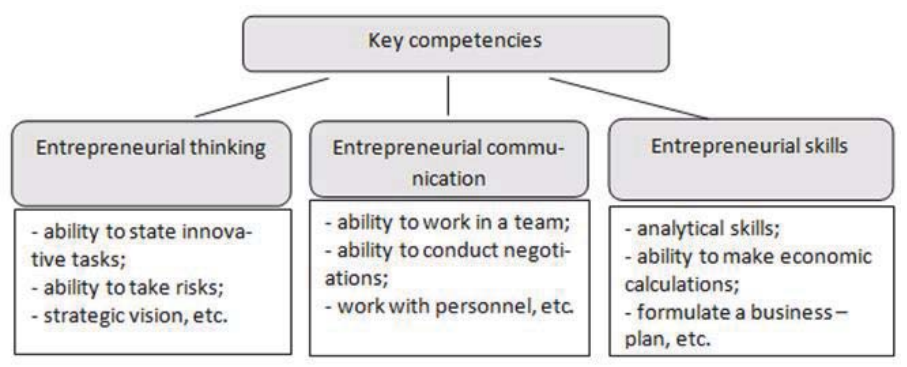

Figure 1. Key competencies of entrepreneurship education, developed by the author.

Educational programs in entrepreneurship offered by the leading universities have the same following characteristics:

1. Wide diversification of educational programs on entrepreneurship. Most of higher educational institutions have created institutional chain of forming entrepreneurial competencies: starting from short-terms courses/programs developing basic skills in the field of entrepreneurship to maser and PhD research programs. Each of analyzed institutions offers several entrepreneurship programs that differ in terms of effort (short and long-term programs) level of specialization (branch, functional, process); profile (basic, supplementary, etc.). Besides bachelor and master programs all educational institutions under research offer short-term entrepreneurship courses. Forms of these courses can be different depending on the type of educational organization, type of main educational programs, qualitative characteristics of innovative infrastructure and external business - environment. It can be a series of open lectures and experience exchange; series of elective courses and master - classes on entrepreneurship; intensive short - term entrepreneurial activity stimulation courses; idea commercialization programs; summer entrepreneurial schools; trainings, etc.

2. A large proportion of disciplines forming (developing) entrepreneurial thinking and oriented towards "building an entrepreneur", such as: creativity and innovation; discover your inner entrepreneur; creative thinking; presentation training; creativity development; etc.

3. Practice oriented form of knowledge check (usually real business - project). Knowledge check format combines successful mastering all disciplines and modules and a particular business - project, which is defended in front of practical experts, potential investors and venture funds representatives.

4. A large proportion of lecturers - entrepreneurs. Lecturers giving entrepreneurship training programs can be subdivided into 4 groups: lecturers - entrepreneurs; lecturers - practical experts; lecturers - academics; lecturers - administrators.

Lecturers - entrepreneurs and lecturers - practical experts are the key figures in forming entrepreneurial competencies of leading universities in terms of entrepreneurship education. Quite often the main criterion in choosing lecturers for entrepreneurship course is their experience of working in entrepreneurial sphere.

5. Use of active educational technologies. In order to form competencies mentioned above the following technologies can be used: online training, design thinking, team facilitation, business game, cases instead of lectures and research articles instead of textbooks.

\subsection{Supporting entrepreneurial activities with the help of developed infrastructure}

Formation of entrepreneurial competencies is supported by a chance to implement them in the framework of special infrastructure elements (business - incubators, accelerators, techno-parks, etc.) (Figure 2).

Leadership training infrastructure in entrepreneurship education has many similarities. One of the main elements of the infrastructure is specialized institute or entrepreneurship center in charge of forming teaching courses and programs in entrepreneurship. Entrepreneurship centers frequently fulfil key task of forming entrepreneurial competencies. Besides educational functions entrepreneurship centers can support start-up programs, organize conferences, competitions and business ideas festivals, etc., issue copyright license for inventions, etc.

Entrepreneurship centers are usually integrated with other elements of innovational infrastructure: network communities, technology transfer departments; business - incubators and sometimes techno-parks.

Technological licensing center/department is an important element of the infrastructure. It supports technology 
transfer process and communication between research (science) and business.

Techno-parks are not the main element of entrepreneurship training infrastructure though for some major universities (particularly technically oriented) they play an important role in the infrastructure.

Entrepreneurship training infrastructure often includes business excavators and business - accelerators. The main task of business - incubator is to facilitate successful development of businesses created by young entrepreneurs. Accelerators are short-term programs aimed at supporting start-ups which are initiated on the basis of business incubators and techno-parks. For a short period of time project team finds itself in an environment that allows for speedy creation of a project or project prototype strong enough to enter the market and attract investments.

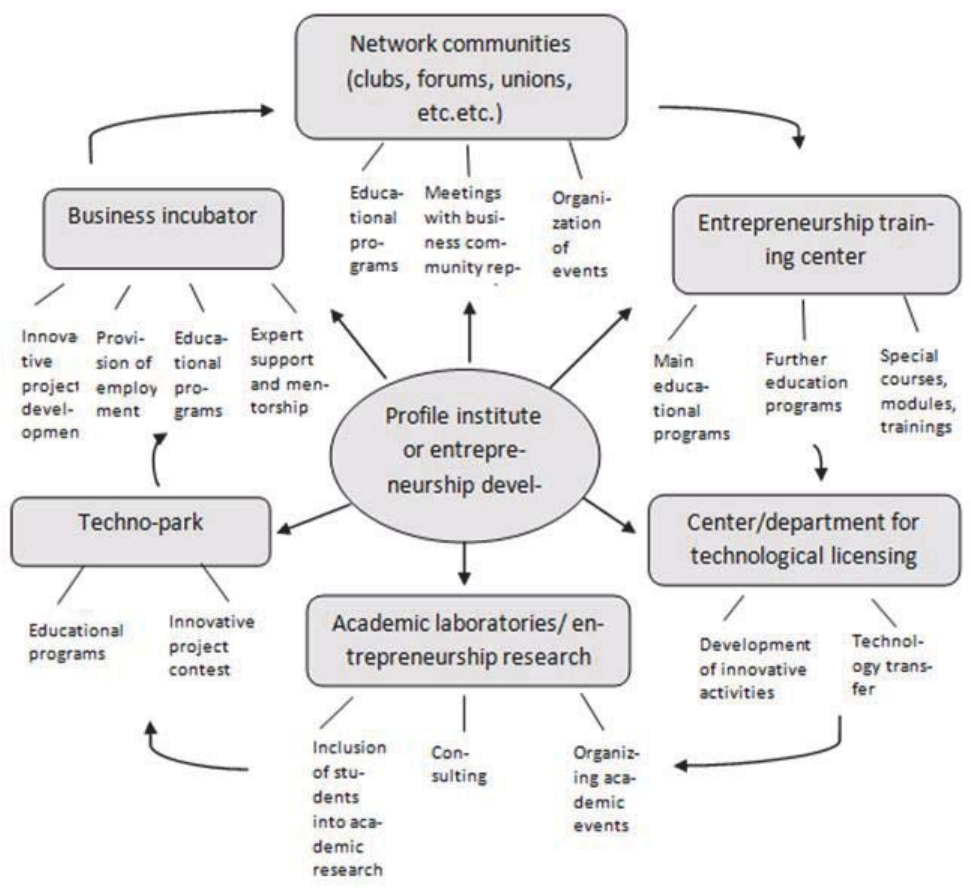

Figure 2. Entrepreneurship education infrastructure at the leading universities, designed by the author.

\subsection{Conducting academic research in the field of entrepreneurship.}

All educational institutions support projects on academic research in the field of entrepreneurship, formulate research topics in the field of entrepreneurship development and actively involve students into the research process. We can identify several research trends supported by leading entrepreneurship education structures: entrepreneurial instruments; markets and competitiveness factors; entrepreneurial behavior; innovative processes; fundamental economic problems.

Leading universities in the field of entrepreneurial behavior usually exist in an environment stimulating research and project activities of the students. All of the educational programs we have analyzed offer competitions, conferences, business games, etc. on the regular basis. The most wide - spread event is student project/start-up competition (business - ideas, innovative projects, business - plans, business models, etc.). Competition winners get an opportunity to implement their project (grants, money, etc.).

Some universities conduct annual Olympiads and nosiness games for student teams. It is obligatory to conduct conferences on entrepreneurial topics. More than half of the universities conduct Annual entrepreneurship weeks. In general leading universities organize up to 20 entrepreneurship events per year. 


\subsection{Developing communicational space for entrepreneurial networking.}

The next important element of entrepreneurship training system is network community: entrepreneurship clubs, forums, young entrepreneurs' unions, etc.

Such associations functions at almost all universities and facilitate close communication of entrepreneurial community of the universities, organize meetings and events. An important role in the functioning of such communities is played by alumni. In most of the analyzed organizations entrepreneurship training infrastructure includes different events aimed at improving networking skills and developing contacts, meeting-places with investors and coaching programs are organized.

\section{Discussion and Conclusions}

Therefore the research on the leading entrepreneurship training universities has demonstrated several key educational program efficacy factors:

- broad diversification of educational programs on forming entrepreneurial competencies;

- presence of institutions providing inclusion of entrepreneurial community representatives into the teaching process;

- opportunity to start business simultaneously with mastering educational program;

- systematic inclusion of students into the interaction with real-life economy and science. Figure 3.

The main features of forming entrepreneurial competencies within the best educational programs are given in the

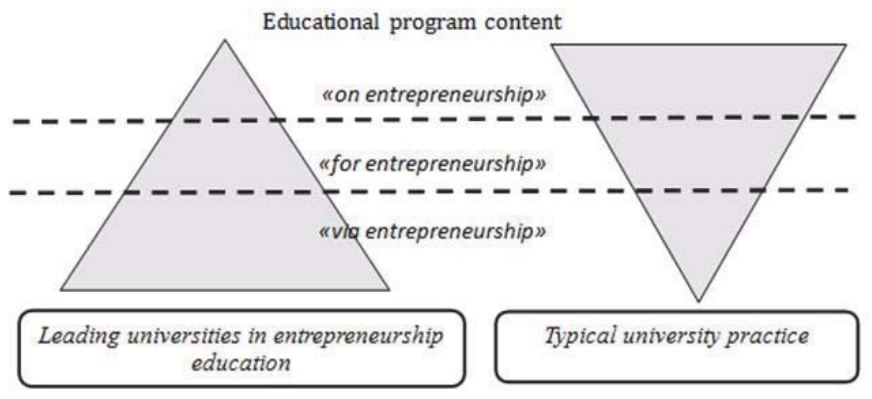

Figure 3. Comparison of approaches to forming entrepreneurial competencies at the universities.

Therefore the key factor of successful formation of entrepreneurial competence is the presence of a full educational cycle an entrepreneurship support starting from basic knowledge transfer to real support of aspiring entrepreneurs and frequently further consulting services to a real business.

According to the results of conducted research on the leading entrepreneurship training programs the following conclusions have been made:

1. In terms of forming entrepreneurial competencies leading universities offer complex training. Entrepreneurship education includes: training, provision of necessary knowledge and ability to apply tit in practice; support of entrepreneurial activities with the help of developed infrastructure; studying academic aspect of entrepreneurship development; construction and support of student, research and entrepreneurial networks.

2. Most universities design institutional chain of forming entrepreneurial competencies: from short-terms courses/programs forming initial entrepreneurial skills to master and doctoral research programs. Each of analyzed universities offers several different entrepreneurship programs different in terms of effort (long-term, short-term, etc.), specialization (branch, functional, processual) and profile (basic, supplementary, etc.), etc.

3. Formation of entrepreneurial competencies is supported by opportunity to implement them in the framework of special infrastructure elements (business - incubators, accelerators, techno-parks, etc.).

4. One of the main elements of entrepreneurship education infrastructure is a special institution or entrepreneurship center in charge of developing teaching courses and programs on entrepreneurship. These 
branches usually solve key tasks on forming entrepreneurial competencies, accumulate new supplementary teaching programs, projects and initiatives.

5. Leading educational organizations in the field of entrepreneurship education can render financial support to entrepreneurs - students by means of picking the best project and ideas. Most of analyzed universities have structures supporting innovative entrepreneurial aspirations of their students by means of financial or other resources or incorporating business - incubators, techno-parks, foundations, grants and other opportunities.

6. Majority of analyzed organizations organize different events on networking and establishment of new contacts, offer opportunities for meeting investors and coaching programs.

7. An important factor is systematic conducting of different events related to entrepreneurship and its development: business - project competitions, trainings and seminars, business games, meetings with entrepreneurs, conferences, forums, youth schools, etc.

8. All educational institutions support research projects in the field of entrepreneurship, formulate research topics on entrepreneurship development and actively involve students onto the research process.

\section{Acknowledgment}

The research is supported by the collaborative Program of the Ural Federal University named after the first President of Russia B.N.Yeltsin and Ural Branch of the Russian Academy of Sciences, Project No14-921-6-3 "Modeling of entrepreneurial strategies in the information-oriented society" and by Russian Foundation for Humanities grant RFH № 15-02-18003 Experimental study of the impact of competitive financing of scientific activity.

\section{References}

Bisk, L. (2002). Formal entrepreneurial mentoring: the efficacy of third party managed programs. Career Development International, 7 (5), 262-270

Cope, J., \& Watts, G. (2000). Learning by doing - An exploration of experience, critical incidents and reflection in entrepreneurial learning. International Journal of Entrepreneurial Behaviour and Research, 6 (3), 104-124

Franovskaya, G. N. (2013). Entrepreneurship education: peculiarities and objectives. Voronezh State University Herald. Series: Economics and management, 1, 190-194.

Khachin, S. V., Kizeev, V. M., \& Ivanchenko, M.A. (2012). Experience of Tomsk Polytechnic University in the field of engineering entrepreneurship training. World of education - education in the world, 4, 13-143.

Kirby, D. A. (2007). Changing the Entrepreneurship Education Paradigm. In Handbook of Research in Entrepreneurship Education, Vol. 1, A. Fayolle, A. (Ed.), 21-45. Cheltenham, UK: Edward Elgar

Mashaw, B. (2012). A model for measuring effectiveness of an online course. Decision Sciences Journal of Innovative Education, 10 (2), $189-221$

Mills, J., Barakat, S., \& Vyakarnam, S. (2010). The impact of e-learning strategies for entrepreneurship education. The Institute of Small Business and Enterprise (ISBE) Annual Conference, London

Pittaway, L., Missing, C., Hudson, N., \& Maragh, D. (2009). Entrepreneurial Learning through action: a case study of the Six-Squared programme. Action Learning: Research and Practice, 6 (3), 265-288

Safin, R. S., Matukhin, E. L., Shaydulina, A. R., \& Zyalaeva, R. G. (2012). Innovational entrepreneurship education in the system of continuous professional education. Kazan pedagogical journal, 5-6(95), 79-96.

Scherbakova, E. A. (2012). Innovative approach to entrepreneurship training. Sothern Russia State Technical University (Novocherkassk Polytechnic Institute) Herald. Series: Social and economic sciences, 3, 83-86.

Shirokova, G. V., \& Kulikova, A. V. (2011). Global research on students' entrepreneurial spirit: national report, Moscow: NRU HSE

Vlasov, M.V. (2004). Knowledge Generation Managing at Universities. Mediterranean Journal of Social Sciences, 6(1), 453-458.

Zaripova, N.S. (2014). Entrepreneurship training in the modern socio-cultural environment. Information and education: communications limits, 6 (14), 220-222.

Zhang, J., \& Hamilton, E. (2010). Entrepreneurship Education for Owner-Managers: The Process of Trust Building for an Effective Learning Community, Journal of Small Business and Entrepreneurship, 23 (2), 249-270 